\title{
Análise da Variabilidade Genética de Duas Cultivares Raminad Str. 3 Utilizadas como Diferenciadoras de Raças de Pyricularia grisea
}

\author{
João L. Nunes Maciel ${ }^{1}$, Paula C. Silvério Rodrigues ${ }^{1}$, Paulo A. Gomes² \& Marcelo Gravina Moraes ${ }^{2}$ \\ ${ }^{1}$ Estação Experimental do Arroz, Instituto Rio-Grandense do Arroz (EEA-IRGA), CEP 94930-030, Cachoeirinha, RS, \\ e-mail: jomac_irga@redemeta.com.br; ${ }^{2}$ Departamento de Fitossanidade, Faculdade de Agronomia, Universidade Federal \\ do Rio Grande do Sul, Cx. Postal 776, CEP 90001-970, Porto Alegre, RS, e-mail: mgm@ufrgs.br
}

(Aceito para publicação em 01/06/2004)

Autor para correspondência: João L. Nunes Maciel

MACIEL, J.L.N., RODRIGUES, P.C.S., GOMES, P.A. \& MORAES, M.G. Análise da variabilidade genética de duas cultivares de Raminad Str. 3 utilizadas como diferenciadoras de raças de Pyricularia grisea. Fitopatologia Brasileira 29:631-637. 2004.

\section{RESUMO}

O conhecimento sobre a ocorrência e distribuição de raças do fungo Pyricularia grisea é um importante aspecto a ser considerado em programas de melhoramento genético de arroz (Oryza sativa). No entanto, para que a identificação das raças seja correta e passível de comparações com outros levantamentos é necessário que os genótipos utilizados apresentem as mesmas características genéticas. O presente trabalho foi realizado com os objetivos de comparar a variação genética entre dois genótipos identificados como pertencentes à cultivar Raminad Str. 3, que é uma das oito cultivares utilizadas como direnciadoras de raças de $P$. grisea, e examinar a composição de raças deste fungo no estado do Rio Grande do Sul. Constatou-se a amplificação de fragmentos polimórficos em 20 dos 39 marcadores microssatélites utilizados para verificar a pureza genética de dois genótipos de arroz identificados como sendo a cultivar Raminad Str. 3. A identificação das raças baseou-se na reação das oito cultivares diferenciadoras de raças submetidas à inoculação com 85 isolados monospóricos de $P$. grisea, provenientes de 14 municípios produtores de arroz no Rio Grande do Sul. A avaliação do grau de infecção foi realizada de acordo com a escala preconizada pelo sistema internacional de avaliação de doenças do arroz, 14 dias após a inoculação.

Palavras-chave adicionais: Oryza sativa, Magnaporthe grisea, brusone do arroz, resistência.

\section{ABSTRACT}

Analysis of the genetic variability of two Raminad Str. 3 cultivars used to differentiate Pyricularia grisea races

The knowledge of the occurrence and distribution of races of Pyricularia grisea is important in rice (Oryza sativa) breeding programs. However, for the correct identification of the races of the pathogen and to compare them with other reports, it is necessary to utilize race differential genotypes that exhibit identical genetic characteristic and source. The main objective of this work was compare the genetic variation of two genotypes of Raminad Str. 3 utilized as one of the eight international differentials and to examine the race composition of P. grisea in the State of Rio Grande do Sul, Brazil. Of 39 microsatellite markers used to verify the genetic differences between the two genotypes identified as the Raminad Str. 3, 20 exhibited polymorphism. The race determination was based on the reaction of differentials submitted to inoculation with 85 monosporic isolates from 14 rice growing municipalities of Rio Grande do Sul. The infection types were scored according to the standard evaluation international system for rice diseases, 14 days after inoculation.

\section{INTRODUÇÃO}

No Rio Grande do Sul, a principal doença que ocorre nas lavouras de arroz (Oryza sativa L.) irrigado é a brusone, a qual é causada pelo fungo Pyricularia grisea (Cooke) Sacc. (Reunião..., 2001). Até o final da década de 1980, de acordo com Ribeiro (1989), 3 a 5\% das lavouras do estado eram atingidos anualmente pela doença. Infelizmente, este levantamento não tem sido atualizado nas últimas safras. Embora exista uma série de fatores que podem favorecer a ocorrência da brusone, a pouca disponibilidade de cultivares resistentes aumenta as possibilidades de epidemias e de incremento dos prejuízos causados pela doença.

A obtenção de cultivares resistentes à brusone tem sido um dos objetivos dos programas de melhoramento genético de arroz (PMGAs) em todo o mundo. Entretanto, após alguns anos de cultivo contínuo e intenso, as cultivares normalmente têm sua resistência perdida, o que tem sido atribuído à grande variabilidade do fungo $P$. grisea (Correa-Victoria \& Zeigler, 1993; Levy et al., 1993). Assim, conhecer o grau de variabilidade da população de $P$. grisea é um aspecto a ser considerado pelos PMGAs, pois é importante que os genótipos gerados sejam resistentes às diversas raças do patógeno que ocorrem no local de plantio das novas cultivares.

O critério mais utilizado para classificar os isolados de $P$. grisea é o padrão racial baseado na reação de oito cultivares de arroz submetidas à inoculação com o patógeno (Atkins et al., 1967; Ling \& Ou, 1969). A resposta destes genótipos, os quais constituem o conjunto internacional de cultivares diferenciadoras de raças, permite classificar o fungo 
em 256 raças pertencentes a nove grupos distintos, subseqüentemente designados de IA até IH (Atkins et al., 1967). Levantamentos realizados na América do Sul verificaram que na Colômbia, o grupo de raças predominante é o IA e, no Brasil, IA e IG, em regiões de plantio de arroz irrigado (Ribeiro \& Terres, 1987), e IB, em regiões de arroz de sequeiro (Prabhu et al., 1992; Prabhu et al., 2002).

No entanto, para que a identificação de raças de $P$. grisea seja adequada, é necessário que os diferentes levantamentos sobre a ocorrência de raças do patógeno utilizem sempre as mesmas cultivares, ou seja, com nenhuma variação na pureza genética. Filippi \& Prabhu (2001) afirmam que, na América do Sul, têm sido utilizados dois genótipos distintos como sendo a cultivar Raminad Str. 3, uma das oito cultivares que compõe conjunto internacional de cultivares diferenciadoras de raças. Ainda, de acordo com Filippi \& Prabhu (2001), um desses genótipos é originário do Brasil e outro da Colômbia. Se esta proposição for confirmada, é possível que a utilização de genótipos distintos como sendo iguais seja a causa das discrepâncias observadas entre a prevalência dos grupos de raças do fungo ocorrentes nos dois países, uma vez que a reação da cultivar Raminad Str. 3. determina se os isolados pertencem ao grupo IA ou IB. A pureza genética dos dois possíveis genótipos pode ser verificada através da utilização de técnicas de biologia molecular. Nesse aspecto, a amplificação de regiões de microssatélites tem sido apontada como uma das mais eficientes estratégias de utilização de marcadores moleculares de DNA para distinguir genótipos de uma mesma espécie de planta (Disconzi, 2002). Uma das vantagens mais importantes que os marcadores de microssatélites apresentam é a possibilidade de comparar genótipos de uma mesma espécie vegetal, entre as 34 em que a presença desses marcadores já foi constatada (Morgante \& Olivieri, 1993). Além disso, esses marcadores também apresentam grande capacidade para gerar polimorfismo (Taramino \& Tyngey, 1996).

Assim, o presente trabalho foi realizado com os objetivos de comparar, por meio de marcadores moleculares baseados na amplificação de regiões de microssatélites, a variação genética de dois genótipos de arroz identificados como sendo a cultivar Raminad Str. 3 e verificar a ocorrência de raças de $P$. grisea na cultura do arroz irrigado no Rio Grande do Sul.

\section{MATERIAL E MÉTODOS}

\section{Análise da variabilidade através de microssatélites}

O DNA de duas amostras de sementes da cultivar Raminad Str. 3, uma procedente do CIAT e outra da EMBRAPA-CNPAF, foi submetido a reações de PCR utilizando 39 pares de oligonucleotídeos iniciadores baseados em marcadores de microssatélites. Inicialmente, dez sementes de cada amostra foram colocadas para germinar em placas de Petri contendo papel-filtro umedecido com água destilada, a $25^{\circ} \mathrm{C}$, por cinco dias. Após este período, coleóptilos e folíolos foram triturados em nitrogênio líquido para que o DNA das amostras fosse extraído conforme os procedimentos descritos por Nelson (1993). Os oligonucleotídeos iniciadores foram escolhidos baseando-se no estudo realizado por Chen et al. (1997) procurando-se selecionar marcadores de todos os cromossomos que compõe o genoma do arroz (Tabela 1). Em cada reação de $13 \mu \mathrm{l}$, feitas em termociclador MJ Research (tipo Minicycler TM), foram utilizadas $50 \eta \mathrm{g}$ do DNA genômico de cada uma das duas amostras, $1 \mathrm{X}$ tampão (20 $\mathrm{mM}$ de Tris- $\mathrm{HCl} 75 \mathrm{mM}$ [pH 8,0] e $50 \mathrm{mM} \mathrm{KCl}$ ), 1,5 mM de $\mathrm{MgCl}_{2}, 0,2 \mathrm{mM}$ de cada dNTP, 1,0 U de polimerase AmpliTaq (Invitrogen, Life Technologies) e $0,4 \mu \mathrm{M}$ de cada oligonucleotídeo iniciador. A amplificação do DNA foi realizada através do aquecimento a $94{ }^{\circ} \mathrm{C}$ por $5 \mathrm{~min}$, e 35 ciclos a: $94{ }^{\circ} \mathrm{C}$ por $1 \mathrm{~min} ; 55^{\circ} \mathrm{C}$ por 1 min e $72{ }^{\circ} \mathrm{C}$ por $2 \mathrm{~min}$. No final, cada reação foi submetida à temperatura de $72{ }^{\circ} \mathrm{C}$ por $5 \mathrm{~min}$. O DNA amplificado das amostras foi desnaturado a $95{ }^{\circ} \mathrm{C}$ por $5 \mathrm{~min}$, separado por eletroforese em gel desnaturante de poliacrilamida a $5 \%$ (acrilamida:bisacrilamida; 19:1), em tampão TBE 1X (89 mM Tris; 89 mM de ácido bórico; 2 mM de EDTA pH 8,3), sendo que a revelação foi realizada com nitrato de prata de acordo com os procedimentos preconizados por Bassam et al. (1991).

\section{Obtenção de isolados monospóricos e preparo de inóculo}

Entre os anos de 1996 e 2001, plantas de arroz com sintomas de brusone na folha e/ou na panícula foram coletadas de lavouras e de parcelas experimentais de arroz instaladas no Rio Grande do Sul. Folhas, colmos ou panículas foram recortadas e colocadas em câmara úmida, a $27^{\circ} \mathrm{C}$, por $24 \mathrm{~h}$. Nestas condições, ocorreu a esporulação do patógeno nas lesões permitindo que se realizasse, com o auxílio de um estereoscópio e de uma agulha entomológica, a transferência de esporos para placas de Petri contendo o meio de cultura ágar-água. Após $24 \mathrm{~h}$, a $27^{\circ} \mathrm{C}$, entre um a quatro esporos germinados em cada amostra foram individualmente transferidos para placas de Petri contendo meio de cultura sólido de arroz polido (SAP) descrito por Tuite (1969). Depois de permanecerem a $28{ }^{\circ} \mathrm{C}$, por seis a oito dias, as colônias obtidas foram utilizadas como fonte para futuras transferências do fungo.

A preservação dos isolados monospóricos foi realizada através do preenchimento de placas de Petri, contendo meio $\mathrm{SAP}$, com vários pedaços de papel-filtro esterilizados $(2 \times 2$ $\mathrm{cm})$. Após, pequenos agregados de micélio do fungo (2-3 mm), obtidos através da raspagem das colônias crescidas em meio SAP, foram depositados em cada um dos pedaços do papelfiltro. Após a incubação por seis a oito dias, a $28^{\circ} \mathrm{C}$, os pedaços de papel foram armazenados $\mathrm{a}-20{ }^{\circ} \mathrm{C}$.

A partir de papéis-filtro contendo o fungo preservado, obteve-se colônias puras dos isolados monospóricos de $P$. grisea em meio SAP. A superfície do meio, contendo a cultura do fungo crescido por seis a oito dias, a $28{ }^{\circ} \mathrm{C}$, foi raspada com o auxílio de uma espátula e o micélio retirado das placas de Petri juntamente com 2 a $3 \mathrm{ml}$ de água destilada e autoclavada que foram adicionados logo após a raspagem. Após, as placas foram incubadas a $28^{\circ} \mathrm{C}$, por três a quatro 
dias, propiciando a produção de esporos para ser utilizado em inoculações.

\section{Identificação de raças de Pyricularia grisea}

A identificação das raças do fungo foi realizada de acordo com a proposição de Atkins et al. (1967), inoculandose plantas do conjunto internacional de cultivares diferenciadoras de raças com isolados do fungo. Vinte plantas de cada uma das cultivares Caloro, Dular, Kanto 51, NP 125, Raminad Str. 3, Shao tia tsao, Usen e Zenith, obtidas a partir de sementes oriundas do Centro Internacional de Agricultura Tropical (CIAT), foram distribuídas em dois vasos contendo solo e submetidas à inoculação com cada um dos isolados utilizados no experimento. Aplicou-se nitrogênio na proporção correspondente a $180 \mathrm{Kg}$ de N/ha, sob a forma de uréia, em três doses com quantidades iguais aos dez e 16 dias depois do plantio e um dia antes da inoculação. As inoculações foram realizadas quando as plantas apresentavam três a quatro folhas expandidas, com 15 a $25 \mathrm{~cm}$, em torno de 22 dias após o plantio. Em cada câmara de plástico, onde ficavam acondicionados 16 vasos, foram utilizados $20 \mathrm{ml}$ de suspensão com $1,8 \times 10^{5}$ conídios $/ \mathrm{ml}$ de cada isolado. As plantas permaneceram nas câmaras com as tampas abertas durante o dia e fechadas durante a noite, por 14 dias, sob temperaturas de 24 a $28{ }^{\circ} \mathrm{C}$. A reação à doença das oito cultivares foi observada considerando o tipo de lesão e a área foliar afetada de acordo com escala diagramática preconizada pelo sistema internacional de avaliação de doenças do arroz e cujas notas variam de 0 a 9 (International Rice Research Institute, 1996). Os isolados do fungo foram classificados em raças utilizando dois critérios. Em um deles seguiu-se o modelo preconizado por Ling \& Ou (1969) em que notas variando de 4 a 6 , as quais classificam as reações das cultivares como médioresistentes, são consideradas para determinar a raça de cada isolado. No outro critério, a determinação das raças dos isolados baseou-se na ocorrência de reações de compatibilidade, notas de 0 a 3 , ou de incompatibilidade, notas de 4 a 9 .

\section{RESULTADOS E DISCUSSÃO}

Variabilidade genética entre genótipos Raminad Str. 3

Dos 39 pares de oligonucleotídeos iniciadores utilizados, 20 produziram fragmentos polimórficos entre as duas amostras testadas (Tabela 1). A presença (Figura 1A) e a ausência (Figura 1B) de polimorfismo são observadas nos fragmentos amplificados por quatro pares de oligonucleotídeos. O tamanho dos fragmentos amplificados variou de 110 até $225 \mathrm{pb}$.

Os resultados obtidos no presente trabalho reforçam a proposição de que a cultivar Raminad Str. 3 utilizada nos dois países é diferente, sendo que isto tem sido verificado principalmente nas reações fenotípicas dos dois genótipos quando submetidos a inoculações com isolados de $P$. grisea. De acordo com Anne Prabhu (comunicação pessoal), depois de ter sido submetido à inoculação com centenas de isolados de $P$. grisea obtidos do Brasil, a cultivar Raminad Str. 3 procedente da EMBRAPA-CNPAF demonstrou ser resistente a maioria deles. Por outro lado, a reação do genótipo procedente do CIAT caracterizou-se por ser de alta suscetibilidade aos mesmos isolados. Além disso, também se deve considerar a diferença verificada na proporção de isolados pertencentes a raças dos grupos IA e IB nos levantamentos em que os genótipos submetidos às inoculações foram as cultivares Raminad Str. 3 utilizadas no presente trabalho. Nestes trabalhos se constatou que na Colômbia, o grupo de raças predominante é o IA e, no Brasil, IA e IG, em regiões de plantio de arroz irrigado (Ribeiro \& Terres, 1987), e IB, em regiões de arroz de sequeiro (Prabhu et al., 1992a; Prabhu et al., 2002b).

Investigações sobre a procedência dos dois genótipos indicaram que o genótipo da EMBRAPA-CNPAF é originário do banco de germomplasma do IRRI, protocolado sob $\mathrm{n}^{\circ}$ ACC32557, enquanto que o genótipo do CIAT tem procedência desconhecida (A. Prabhu, comunicação pessoal). Ainda cabe destacar que apesar das diferenças fenotípicas demonstradas entre os dois genótipos, não há registro que essa diferença tenha sido verificada através de uma análise molecular comparativa.

Os resultados obtidos também permitiram constatar a importância que representa a utilização das mesmas cultivares em diferentes levantamentos sobre a ocorrência de raças de P. grisea. Isto significa afirmar que as oito cultivares de arroz que compõe o conjunto internacional de cultivares diferenciadoras de raças de $P$. grisea devem apresentar a mesma origem genética. Nesse aspecto, como demonstrado neste trabalho, os marcadores moleculares se constituem em importantes ferramentas para certificação das diferenças genéticas das cultivares utilizadas para diferenciar as raças do patógeno.

\section{Identificação de raças}

Os 85 isolados monospóricos testados no experimento foram obtidos de plantas de 35 genótipos de arroz, coletadas em 14 municípios do Rio Grande do Sul. Cerca de 95\% dos isolados foram obtidos de cultivares comerciais e o restante de linhagens PMGA do IRGA. Os municípios de onde as plantas foram coletadas estão localizados em importantes regiões orizícolas do estado como a Depressão Central, o Litoral Sul e as Planícies Costeira Externa e Interna.

Quando se utilizou o critério preconizado por Ling \& Ou (1969), que considera as reações médio-resistentes, dos 85 isolados testados, foram identificadas 31 raças de $P$. grisea sendo que a mais encontrada foi a IH-1, com 15 isolados (Tabela 2). A maioria das raças identificadas pertence ao grupo IA, mas também foram encontradas raças dos grupos IB, ID, IE, IF, IH e II. Quando o critério adotado para identificar as raças dos isolados do fungo considerou somente a ocorrência de reações de compatibilidade ou de incompatibilidade, foram encontradas 26 raças, sendo todas pertencentes ao grupo IA, e as mais encontradas foram a IA-45 e a IA-1, com 22 e 8 isolados, respectivamente. 
J.L.N. Maciel et al.

TABELA 1 - Marcadores de microssatélites utilizados e a variação alélica obtida entre locos do genoma da cultivar Raminad Str. 3 de arroz (Oryza sativa)

\begin{tabular}{|c|c|c|c|c|}
\hline \multirow{2}{*}{ Locus } & \multirow{2}{*}{ Cromossomo } & \multicolumn{2}{|c|}{ Seqüência dos oligonucleotídeos iniciadores $(5 \rightarrow 3$ ') } & \multirow{2}{*}{$\begin{array}{l}\text { Amplificação } \\
\text { polimórfica* }\end{array}$} \\
\hline & & Forward & Reverse & \\
\hline RM81 & 1 & GAGTGCTTGTGCAAGATCCA & CTTCTTCACTCATGCAGTTC & - \\
\hline RM212 & 1 & CCACTTTCAGCTACTACCAG & CACCCATTTGTCTCTCATTATG & - \\
\hline RM220 & 1 & GGAAGGTAACTGTTTCCAAC & GAAATGCTTCCCACATGTCT & + \\
\hline RM238 & 1 & GATGGAAAGCACGTGCACTA & ACAGGCAATCCGTAGACTCG & - \\
\hline RM246 & 1 & GAGCTCCATCAGCCATTCAG & CTGAGTGCTGCTGCGACT & - \\
\hline RM259 & 1 & TGGAGTTTGAGAGGAGGG & CTTGTTGCATGGTGCCATGT & + \\
\hline RM240 & 2 & CCTTAATGGGTAGTGTGCAC & TGTAACCATTCCTTCCATCC & - \\
\hline RM263 & 2 & CCCAGGCTAGCTCATGAACC & GCTACGTTTGAGCTACCACG & - \\
\hline RM55 & 3 & CCGTCGCCGTAGTAGAGAAG & TCCCGGTTATTTTAAGGCG & + \\
\hline RM227 & 3 & ACCTTTCGTCATAAAGACGAG & GATTGGAGAGAAAAGAAGCC & + \\
\hline RM231 & 3 & CCAGATTATTTCCTGAGGTC & CACTTGCATAGTTCTGCATTG & + \\
\hline RM241 & 4 & GAGCCAAATAAGATCGCTGA & TGCAAGCAGCAGATTTAGTG & + \\
\hline RM252 & 4 & TTCGCTGACGTGATAGGTTG & ATGACTTGATCCCGAGAACG & + \\
\hline RM255 & 4 & TGTTGCGTGTGGAGATGTG & CGAAACCGCTCAGTTCAAC & - \\
\hline RM249 & 5 & GGCGTAAAGGTTTTGCATGT & ATGATGCCATGAAGGTCAGC & - \\
\hline RM30 & 6 & GGTTAGGCATCGTCACGG & TCACCTCACCACACGACACG & + \\
\hline RM225 & 6 & TGCCCATATGGTCTGGATG & GAAAGTGGATCAGGAAGGC & + \\
\hline RM253 & 6 & TCCTTCAAGAGTGCAAAACC & GCATTGTCATGTCGAAGCC & + \\
\hline RM82 & 7 & TGCTTCTTGTCAATTCGCC & CGACTCGTGGAGGTACGG & - \\
\hline RM214 & 7 & CTGATGATAGAAACCTCTTCTC & AAGAACAGCTGACTTCACAA & - \\
\hline RM234 & 7 & ACAGTATCCAAGGCCCTGG & CACGTGAGACAAAGACGGAG & - \\
\hline RM248 & 7 & TCCTTGTGAAATCTGGTCCC & GTAGCCTAGCATGGTGCATG & + \\
\hline RM25 & 8 & GGAAAGAATGATCTTTTCATGG & CTACCATCAAAACCAATGTTC & - \\
\hline RM38 & 8 & ACGAGCTCTCGATCAGCCTA & TCGGTCTCCATGTCCCAC & - \\
\hline RM210 & 8 & TCACATTCGGTGGCATTG & CGAGGATGGTTGTTCACTTG & + \\
\hline RM223 & 8 & GAGTGAGCTTGGGCTGAAAC & GAGGCAAGTCTTGGCACTG & - \\
\hline RM201 & 9 & CTCGTTTATTACCTACAGTACC & СТACСТCСТTTCTAGACCGATA & - \\
\hline RM245 & 9 & ATGCCGCCAGTGAATAGC & CTGAGAATCCA ATT ATCTGGG & + \\
\hline RM257 & 9 & CAGTTCCGAGCAAGAGTACTC & GGATCGGACGTGGCATATG & - \\
\hline RM222 & 10 & CTTAAATGGGCCACATGCG & CAAAGCTTCCGGCCAAAAG & + \\
\hline RM228 & 10 & CTGGCCATTAGTCCTTGG & GCTTGCGGCTCTGCTTAC & - \\
\hline RM239 & 10 & TACAAAATGCTGGGTACCCC & ACATATGGGACCCACCTGTC & - \\
\hline RM258 & 10 & TGCTGTATGTAGCTCGCACC & TGGCCTTTAAAGCTGTCGC & + \\
\hline RM202 & 11 & CAGATTGGAGATGAAGTCCTCC & CCAGCAAGCATGTCAATGTA & + \\
\hline RM206 & 11 & CCCATGCGTTTAACTATTCT & CGTTCCATCGATCCGTATGG & - \\
\hline RM209 & 11 & ATATGAGTTGCTGTCGTGCG & CAACTTGCATCCTCCССТCC & + \\
\hline RM224 & 11 & ATCGATCGATCTTCACGAGG & TGCTATAAAAGGCATTCGGG & + \\
\hline RM235 & 12 & AGAAGCTAGGGCTAACGAAC & TCACCTGGTCAGCCTCTTTC & + \\
\hline RM247 & 12 & TAGTGCCGATCGATGTAACG & CATATGGTTTTGACAAAGCG & + \\
\hline
\end{tabular}

*Os sinais $+\mathrm{e}-$ significam que as amplificações foram polimórficas ou monomórficas, respectivamente.

Para fazer a comparação dos resultados obtidos no presente trabalho com os resultados obtidos em outros levantamentos é necessário considerar o critério adotado para classificar as raças do patógeno. Nos únicos dois levantamentos realizados anteriormente sobre a ocorrência de raças no Rio Grande do Sul, as reações médio-resistentes foram consideradas (Ribeiro, 1980; Ribeiro \& Terres, 1987). Nesses casos, a proporção de raças do grupo IA foi menor do que se as reações médio-resistentes fossem desconsideradas. Por outro lado, nos levantamentos realizados na Colômbia (Correa-Victoria \& Zeigler, 1993; Levy et al., 1993), que embora não tenham considerado as reações médio-resitentes para identificação das raças do fungo, verificou-se uma proporção relativamente alta de isolados pertencentes a raças 
Análise da variabilidade genética de duas cultivares Raminad Str. 3...

TABELA 2 - Classificação racial dos isolados de Pyricularia grisea e características das amostras de plantas de arroz (Oryza sativa) das quais foram obtidos

\begin{tabular}{|c|c|c|c|c|c|c|c|c|c|}
\hline \multirow[b]{2}{*}{ Isolado } & \multicolumn{2}{|c|}{ Raça } & \multicolumn{2}{|c|}{ Amostra $^{2}$} & \multirow[b]{2}{*}{ Isolado } & \multicolumn{2}{|c|}{ "Raça } & \multicolumn{2}{|c|}{ Amostra } \\
\hline & Critério $1^{1}$ & Critério 2 & $\begin{array}{l}\text { Parte da } \\
\text { planta }\end{array}$ & Genótipo & & Critério 1 & Critério 2 & $\begin{array}{c}\text { Parte da } \\
\text { planta }\end{array}$ & Genótipo \\
\hline 111 & IA-103 & IA-1 & Folha & Linhagem IRGA & 161 & IB-61 & IA-41 & Folha & IRGA 416 \\
\hline 271 & IA-109 & IA-9 & Folha & Formosa & 224 & IB-62 & IA-45 & Folha & EEA 405 \\
\hline 278 & IA-109 & IA-45 & Folha & EEA 405 & 10 & IB-63 & IA-35 & Folha & Taim \\
\hline 88 & IA-121 & IA-65 & Panícula & IRGA 416 & 331 & ID-11 & IA-331 & Folha & Mars \\
\hline 96 & IA-123 & IA-1 & Folha & Chuí & 335 & ID-13 & IA-13 & Folha & Dular \\
\hline 105 & IA-123 & IA-35 & Folha & BR-IRGA 415 & 350 & ID-13 & IA-45 & Folha & IRGA 422 CL \\
\hline 130 & IA-123 & IA-17 & Panícula & El Paso L 144 & 150 & ID-7 & IA-1 & Folha & Dular \\
\hline 166 & IA- 123 & IA-1 & Folha & IRGA 416 & 279 & IE-3 & IA-17 & Folha & Caloro \\
\hline 196 & IA-123 & IA-1 & Folha & IRGA 408 & 163 & IE-7 & IA-17 & Panícula & IRGA 416 \\
\hline 216 & IA- 123 & IA- 57 & Folha & Ligeirinho & 59 & IF-3 & IA- 67 & Folha & El Paso L 144 \\
\hline 266 & IA-123 & IA-1 & Folha & Chuí & 106 & IF-3 & IA-51 & Folha & BR-IRGA 409 \\
\hline 267 & IA-123 & IA- 81 & Panícula & E-39 Agrisul & 148 & IF -3 & IA- 83 & Folha & IAC 47 \\
\hline 356 & IA-123 & IA-81 & Folha & Kanto 51 & 195 & IF-3 & IA-17 & Folha & BR-IRGA 415 \\
\hline 57 & IA-124 & IA-35 & Folha & BR-IRGA 409 & 217 & IF-3 & IA-1 & Folha & BR-IRGA 414 \\
\hline 187 & IA-124 & IA-51 & Panícula & BR-IRGA 414 & 357 & IF-3 & IA-25 & Folha & Kanto 51 \\
\hline 341 & IA-124 & IA-81 & Folha & EEA 406 & $206 / 193 / 154$ & IF-3 & IA-91 & Panícula & IRGA 416 \\
\hline 75 & IA-127 & IA-91 & Panicula & BR-IRGA 409 & 78 & IF-4 & IA-17 & Panícula & El Paso L 144 \\
\hline 102 & IA-127 & IA -83 & Folha & Taquari & 98 & IF-4 & IA-19 & Folha & Farroupilha \\
\hline 108 & IA-127 & IA-17 & Panícula & BR-IRGA 409 & 118 & IF-4 & IA-19 & Folha & BR-IRGA 409 \\
\hline 261 & IA- 127 & IA-41 & Panícula & IRGA 416 & 119 & IF-4 & IA-51 & Folha & Linhagem CIAT \\
\hline 302 & IA-127 & IA-45 & Folha & BR-IRGA 410 & 62 & $\mathrm{IH}-1$ & IA-25 & Folha & BR-IRGA 409 \\
\hline 352 & IA-127 & IA -45 & Panícula & IRGA 416 & 97 & $\mathrm{IH}-1$ & IA-57 & Folha & BR-IRGA 415 \\
\hline $182 / 189 \mathrm{~A}$ & IA-127 & IA-45 & Folha & BR-IRGA 409 & 164 & IH-1 & IA-13 & Folha & EEA 301 \\
\hline 48 & IA- 128 & IA-51 & Folha & BR-IRGA 410 & 270 & IH-1 & IA-45 & Panicula & E-39 Agrisul \\
\hline 211 & IA- 128 & IA-89 & Folha & El Paso L 144 & 273 & IH-1 & IA-45 & Folha & Bico Torto \\
\hline $116 / 127$ & IA-3 & IA-3 & Panícula & BR-IRGA 410 & 306 & IH-1 & IA-45 & Folha & BR-IRGA 409 \\
\hline 177 & IA-33 & IA-35 & Folha & Farroupilha & 314 & $\mathrm{IH}-1$ & IA-45 & Folha & IRGA 421 \\
\hline 333 & IA-41 & IA-9 & Folha & Dular & 318 & IH-1 & IA -45 & Folha & IRGA 417 \\
\hline 188 & IA -43 & IA-43 & Folha & EEA 406 & 326 & IH-1 & IA-45 & Folha & BR-IRGA 410 \\
\hline 337 & IA -45 & IA-9 & Folha & NP 125 & 329 & IH-1 & IA-45 & Folha & BR-IRGA 409 \\
\hline 214 & IA-47 & IA-45 & Folha & Taim & 336 & $\mathrm{IH}-1$ & IA-37 & Folha & Dular \\
\hline 219 & IA -47 & IA -45 & Folha & EEA 404 & 338 & IH-1 & IA-45 & Folha & Raminad Str. 3 \\
\hline 221 & IA-47 & IA-45 & Folha & Caloro & 348 & IH-1 & IA-15 & Panícula & IRGA 421 \\
\hline $182 / 189 \mathrm{~B}$ & IA-63 & IA-61 & Folha & BR-IRGA 409 & 355 & IH-1 & IA-61 & Panícula & IRGA 417 \\
\hline 225 & IB-13 & IA-9 & Folha & EEA 301 & $182 / 189 \mathrm{C}$ & IH-1 & IA-13 & Folha & BR-IRGA 409 \\
\hline 240 & IB-29 & IA-25 & Panícula & Fanny & 947 & II-1 & IA-67 & Folha & BR-IRGA 415 \\
\hline 342 & IB-45 & IA-45 & Folha & IRGA 419 & 110 & II-1 & IA-35 & Folha & Dular \\
\hline 345 & IB-45 & IA-9 & Folha & NP 125 & 115 & II-1 & IA-83 & Panícula & Linhagem IRGA \\
\hline 257 & IB-47 & IA-45 & Panícula & Epagri 108 & 170 & II-1 & IA-45 & Panícula & Epagri 108 \\
\hline $332 \mathrm{~A}$ & IB-47 & IA-33 & Folha & Dular & 269 & II-1 & IA-17 & Folha & E-39 Agrisul \\
\hline $332 \mathrm{~B}$ & IB-47 & IA-1 & Folha & Dular & 276 & II-1 & IA-121 & Folha & Bico Torto \\
\hline 167 & IB-48 & IA -45 & Folha & EEA 201 & 321 & II-1 & IA-45 & Folha & IRGA 417 \\
\hline 223 & IB-48 & IA-47 & Folha & Fanny & & & & & \\
\hline
\end{tabular}

${ }^{1}$ Para determinação da raça de cada isolado, considerou-se somente a ocorrência de reações de compatibilidade ou de incompatibilidade no critério 1, e de reações médio-resistentes no critério 2.

${ }^{2}$ Os isolados foram obtidos das folhas ou panículas de plantas pertencentes a vários genótipos arroz.

do grupo IA (50 a 70\%). Tal situação indica que, no local onde os isolados foram obtidos naquele País, existe uma maior variabilidade do fungo, pelo menos em termos de grupos de raças. Além disso, o genótipo Raminad Str. 3 utilizado no presente trabalho para determinação das raças é originário do CIAT, Colômbia, o que, certamente, influenciou na maior proporção de isolados pertencentes a raças do grupo IA. Infelizmente, é desconhecida a origem genética da cultivar Raminad Str. 3 utilizada nos levantamentos anteriores realizados por Ribeiro (1980) e Ribeiro \& Terres (1987) para 
J.L.N. Maciel et al.

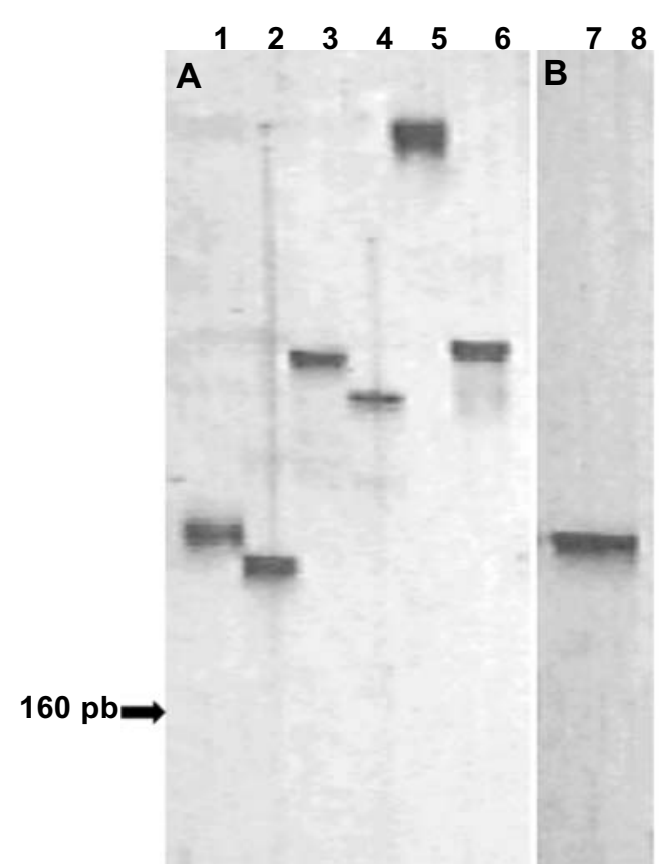

FIG. 1 - Gel de poliacrilamida demonstrando a variação alélica para locos de microssatélites. Os números 1 e $2 ; 3$ e $4 ; 5$ e $6 ; 7$ e 8 representam, respectivamente, fragmentos gerados nos locos RM 259, RM 231, RM 252 e RM 201 a partir do DNA do cultivar Raminad Str. 3 de arroz (Oryza sativa) cujas sementes foram fornecidas pela EMBRAPA (números ímpares) e pelo CIAT (números pares). As letras A e B representam amplificações polimórficas e monomórficas, respectivamente.

determinação das raças de $P$. grisea ocorrentes no Rio Grande do Sul. Entretanto, devido à proporção de isolados do grupo IB ter sido de apenas 7\% no levantamento realizado por Ribeiro \& Terres (1987), é mais provável que a cultivar Raminad Str. 3 utilizada fosse originário da Colômbia.

Outra importante constatação que pode ser obtida pela análise dos dois outros levantamentos realizados sobre a ocorrência de raças de $P$. grisea no Rio Grande do Sul, é a de que persiste no estado uma grande variabilidade do patógeno, embora o número de raças identificadas tenha sido menor do que as 50 relatadas nos levantamentos feitos por Ribeiro (1980) e Ribeiro \& Terres (1987). No entanto, também se deve considerar que a identificação deste maior número de raças foi realizada a partir de amostras coletadas durante 15 anos (1969 a 1985), enquanto que o presente levantamento refere-se a coletas realizadas durante um período de tempo menor (1996 e 2001).

Entre o primeiro e o segundo levantamento realizado por Ribeiro (1980) e Ribeiro \& Terres (1987), respectivamente, já havia sido constatado o incremento da proporção de isolados pertencentes às raças do grupo IA, quando se registrou o aumento de 10 para $28 \%$ na porcentagem de isolados pertencentes a esse grupo de raças. Neste trabalho esta tendência de aumento de raças do grupo IA se confirmou, uma vez que, dependendo do critério adotado para identificação das raças, se determinou que $40 \%$ ou $100 \%$ dos isolados testados pertencem a raças deste grupo. Outra importante constatação verificada foi a ausência de isolados pertencentes a raças dos grupos IC e IG.

É provável que uma das principais causas para ocorrência das variações verificadas na população do fungo, entre os levantamentos anteriores e o presente trabalho, tenha sido provocada pela mudança da base genética das cultivares utilizadas nas lavouras de arroz do Rio Grande do Sul, a qual ocorreu entre o final e início das últimas décadas de 70 e 80 , respectivamente. A partir desse período houve um aumento da área de plantio das cultivares do tipo denominado moderno em detrimento das cultivares dos tipos tradicional e americano. A ausência de isolados pertencentes aos grupos IC e IG provavelmente esteja relacionado a esta mudança na escolha das cultivares a serem plantadas, uma vez que a maioria dos isolados pertencentes aos dois grupos de raças mencionados acima havia sido obtida de plantas da cultivar Bluebelle, que é uma cultivar do tipo americano.

Ribeiro \& Terres (1987) já mencionavam que o incremento de raças do grupo IA, ocorrido entre o primeiro e segundo levantamento, esteve associado com o aumento da área de plantio das cultivares BR-IRGA 409 e BR-IRGA 410, as quais foram as primeiros cultivares do tipo moderno a terem uma área importante de plantio no Rio Grande do Sul. Atualmente, a área de plantio com essas duas cultivares é bem mais reduzida que durante a última década de 80 , sendo que, no estado, na safra 2001-02, o percentual de área plantado com as cultivares BR-IRGA 409 e BR-IRGA 410 foi de 7,77 e $9,05 \%$, respectivamente (Instituto Rio-grandense do Arroz, 2002). No entanto, o plantio de cultivares com fontes de resistência à brusone idênticas a essas duas cultivares pode ter influenciado a manutenção das taxas de crescimento das raças do grupo IA ocorridas no Rio Grande do Sul. Nesse aspecto, cita-se o caso das cultivares El Paso L 144 e IRGA 417 , com o percentual de áreas plantadas no estado de 17,63 e $25,97 \%$ na safra 2001-02, respectivamente, sendo que o primeiro é originário de seleções feitas em plantas da cultivar BR-IRGA 409 e o segundo possui com um de seus progenitores a própria cultivar BR-IRGA 409 (Pedroso, 1980; Instituto Rio-grandense do Arroz, 2003).

A identificação de raças de $P$. grisea ocorrentes em uma região, estado ou país viabiliza a verificação do grau de resistência à doença de genótipos gerados por PMGAs através dos procedimentos de inoculação. Além disso, também permite que seja feito o monitoramento da dinâmica populacional do patógeno em viveiros de infecção de brusone e ao longo do tempo, em condições de plantio de diferentes cultivares. No entanto, submeter muitos genótipos à inoculação de isolados de muitas raças ou monitorar a ocorrência de um número muito elevado de raças são estratégias difíceis de serem executadas. Dessa forma, o emprego de alternativas que permitam classificar o fungo em um menor número de variantes com características de virulência comuns pode facilitar a execução de procedimentos relacionados à obtenção de cultivares resistentes à brusone tais como testes de inoculação e monitoramento da dinâmica 
Análise da variabilidade genética de duas cultivares Raminad Str. 3...

populacional do fungo. Sem dúvida, uma dessas alternativas é também classificar o fungo de acordo com a reação que os isolados do patógeno provocam em linhas isogênicas. Entre esses genótipos, as linhas isogênicas selecionadas por MacKill \& Bonman (1992) são as que mais tem sido utilizadas para verificar o padrão de virulência de $P$. grisea.

\section{AGRADECIMENTOS}

Os autores agradecem à EMBRAPA-CNPAF e ao CIAT, pelo fornecimento de sementes dos cultivares diferenciadores de raças de P. grisea, e ao Dr. Fernando Correa-Victoria, pelas sugestões para execução deste trabalho.

\section{REFERÊNCIAS BIBLIOGRÁFICAS}

ATKINS, J.G., ROBERT, A.L., ADAIR, C.R., GOTO, K., KOSAKA, R., YANAGIDA, P., YAMADA, M. \& MATSUMOTO, S. International set of rice varieties for differentiating races of Pyricularia oryzae. Phytopathology 57:297-301. 1967.

BASSAM, B.J., CAETANO-ANOLLES, G. \& GRESSHOFF, P.M. Fist and sensitive silver staining of DNA in polyacrylamide gels. Analytical Biochemistry 196:80-83. 1991.

CHEN, X., TEMNYKH, S., XU, Y., CHO, Y.G. \& McCOUCH, S.R. Development of a microsatelite framework map providing genome-wide coverage in rice (Oryza sativa L.). Theoretical and Applied Genetics 95:553-57. 1997.

CORREA-VICTORIA, F.J. \& ZEIGLER, R. S. Pathogenic variability in Pyricularia grisea at a rice blast "hot spot" breeding site in eastern Colombia. Plant Disease 77:1029-1035. 1993.

DISCONZI, M.A. Identificação de genes de resistência à brusone (Magnaporthe grisea) em cultivares de arroz (Oryza sativa) utilizando marcadores moleculares. (Dissertação de Mestrado). Porto Alegre. UFRGS. 2002.

FILIPPI, M.C. \& PRABHU, A.S. Phenotypic virulence analysis of Pyricularia grisea isolates from Brazil upland rice cultivars. Pesquisa Agropecuária Brasileira 36:27-35. 2001.

INSTITUTO RIO-GRANDENSE DO ARROZ. Cultivares. Capturado em 09 de maio de 2003. On line. http://www.irga.rs.gov.br/dados.htm. INTERNATIONAL RICE RESEARCH INSTITUTE. Standard evaluation system for rice. $4^{\text {nd }}$ ed. Manila. 1996.

LEVY, M., CORREA-VICTORIA, F.S., ZEIGLER, R.S., XU, S. \& HAMER, J.E. Genetic diversity of the rice blast fungus in a disease nursery in Colombia. Phytopathology 83:1427-1433. 1993.

LING, K.C. \& OU, S.H. Standardization of international race numbers of Pyricularia oryzae. Phytopathology 59:339-342. 1969.

MACKILL, D.J. \& BONMAM, J.M. Inheritance of blast resistance in near-isogenic lines in rice. Phytopathology 82:746-749.1992.

MORGANTE, M. \& OLIVIERI, A.M. PCR-amplified microsatellite as markers in plant genetics. Plant Journal 1:175-182. 1993.

NELSON, J.C. Wheat mapping workshop: laboratory manual. Ithaca. Cornell University. 1993.

PEDROSO, B.A. BR-IRGA 409, Nova cultivar de arroz irrigado. Lavoura Arrozeira 32:18-23. 1979.

PRABHU, A.S., FILIPPI, M.C. \& CASTRO, N. Pathogenic variation among isolates of Pyricularia oryzae affecting rice, wheat and grasses in Brazil. International Journal of Pest Management 38:367371. 1992a.

PRABHU, A.S., FILIPPI, M.C., ARAUJO, L.G. \& FARIA, J.C. Caracterizaçãogenética e fenotípica de isolados de Pyricularia grisea coletados em lavouras das cultivares Epagri 108 e 109 no Estado de Tocantins. Fitopatologia Brasileira 27:566-573. 2002b.

Reunião da Comissão Técnica de Pesquisas de Arroz para o Sul do Brasil. 24. Recomendações. Porto Alegre, RS. 2001.

RIBEIRO, A.S. Controle integrado das doenças do arroz irrigado. Pelotas. EMBRAPA-CPATB. 29p. Circular Técnica, 3. 1989.

RIBEIRO, A.S. Prevalência de raças de Pyricularia oryzae Cav. no Rio Grande do Sul. Pesquisa Agropecuária Brasileira 15:175-82. 1980.

RIBEIRO, A.S. \& TERRES, A.L.S. Variabilidade do fungo Pyricularia oryzae e sua relação com cultivares resistentes à brusone. Pesquisa Agropecuária Brasileira 12:316-321. 1987.

TARAMINO, G. \& TINGEY S.V. Simple sequence repeats for germoplasm analysis and mapping in maize. Genome 39:277-287. 1996.

TUITE, J. Plant Pathological Methods, Fungi and Bacteria. Minneapolis. Burgess Publishing. 1969. 